\title{
Spatial and temporal variations in plant water-use efficiency inferred from tree-ring, eddy covariance and atmospheric observations
}

\author{
Stefan C. Dekker ${ }^{1, *}$, Margriet Groenendijk ${ }^{2, *}$, Ben B. B. Booth ${ }^{3}$, Chris Huntingford ${ }^{4}$, and Peter M. Cox ${ }^{2}$ \\ ${ }^{1}$ Copernicus Institute of Sustainable Development, Faculty of Geosciences, Utrecht University, \\ Heidelberglaan 2, 3584 CS Utrecht, the Netherlands \\ ${ }^{2}$ College of Engineering, Mathematics and Physical Sciences, University of Exeter, North Park Road, \\ Exeter, EX4 4QF, UK \\ ${ }^{3}$ Met Office Hadley Centre, FitzRoy Road, Exeter, EX1 3PB, UK \\ ${ }^{4}$ Centre for Ecology and Hydrology, Benson Lane, Wallingford, OXON, OX10 8BB, UK \\ "These authors contributed equally to this work.
}

Correspondence to: Stefan C. Dekker (s.c.dekker@uu.nl)

Received: 11 February 2016 - Published in Earth Syst. Dynam. Discuss.: 22 February 2016

Revised: 7 June 2016 - Accepted: 13 June 2016 - Published: 28 June 2016

\begin{abstract}
Plant water-use efficiency (WUE), which is the ratio of the uptake of carbon dioxide through photosynthesis to the loss of water through transpiration, is a very useful metric of the functioning of the land biosphere. WUE is expected to increase with atmospheric $\mathrm{CO}_{2}$, but to decline with increasing atmospheric evaporative demand - which can arise from increases in near-surface temperature or decreases in relative humidity. We have used $\Delta^{13} \mathrm{C}$ measurements from tree rings, along with eddy covariance measurements from Fluxnet sites, to estimate the sensitivities of WUE to changes in $\mathrm{CO}_{2}$ and atmospheric humidity deficit. This enables us to reconstruct fractional changes in WUE, based on changes in atmospheric climate and $\mathrm{CO}_{2}$, for the entire period of the instrumental global climate record. We estimate that overall WUE increased from 1900 to 2010 by $48 \pm 22 \%$, which is more than double that simulated by the latest Earth System Models. This long-term trend is largely driven by increases in $\mathrm{CO}_{2}$, but significant inter-annual variability and regional differences are evident due to variations in temperature and relative humidity. There are several highly populated regions, such as western Europe and East Asia, where the rate of increase of WUE has declined sharply in the last 2 decades. Our data-based analysis indicates increases in WUE that typically exceed those simulated by Earth System Models implying that these models are either underestimating increases in photosynthesis or underestimating reductions in transpiration.
\end{abstract}

\section{Introduction}

Plant water-use efficiency (WUE) is the ratio of the $\mathrm{CO}_{2}$ assimilated through photosynthesis (gross primary productivity, GPP), to the water used by plants as the flux of transpiration $\left(E_{\mathrm{T}}\right)$ :

$\mathrm{WUE}=\frac{\mathrm{GPP}}{E_{\mathrm{T}}}$.
Carbon dioxide may affect plants through increases in photosynthesis (Ainsworth and Rogers, 2007; Franks et al., 2013) and possible reductions in transpiration associated with the partial closure of leaf stomatal pores under elevated $\mathrm{CO}_{2}$ (Field et al., 1995; Gedney et al., 2006; Betts et al., 2007). Both of these effects are uncertain though. $\mathrm{CO}_{2}$ fertilization of photosynthesis is often found to be limited by nutrient availability (Norby et al., 2010), and large-scale transpiration may not reduce even with $\mathrm{CO}_{2}$-induced stomatal closure, if plant leaf area index increases enough to counteract reduced 
transpiration from each leaf (Piao et al., 2007). WUE does however appear to be increasing more robustly with $\mathrm{CO}_{2}$, according to both tree-ring (Franks et al., 2013) and eddy covariance flux measurements (Keenan et al., 2013).

Plant photosynthesis and transpiration are coupled through the behaviour of leaf stomatal pores, through which $\mathrm{CO}_{2}$ must diffuse to be fixed during photosynthesis, and through which the transpiration flux escapes to the atmosphere. The combined behaviour of the leaf stomata leads to an environmentally dependent "canopy conductance" that controls both the water and carbon fluxes. As a consequence, both GPP and $E_{\mathrm{T}}$ can be written as the product of a canopy conductance and a concentration gradient, which is sometimes described as an electrical analogue (Cowan, 1972). For GPP, the concentration gradient is the difference between the atmospheric $\mathrm{CO}_{2}$ concentration at the leaf surface $\left(C_{\mathrm{a}}\right)$ and the internal $\mathrm{CO}_{2}$ concentration within plant leaves $\left(C_{\mathrm{i}}\right)$ :

$\mathrm{GPP}=g_{\mathrm{c}}\left(C_{\mathrm{a}}-C_{\mathrm{i}}\right)$,

where $g_{\mathrm{c}}$ is the canopy conductance for $\mathrm{CO}_{2}$.

For $E_{\mathrm{T}}$, the concentration gradient is the difference between the specific humidity of the atmosphere at the leaf surface $\left(q_{\mathrm{a}}\right)$ and the specific humidity inside the plant leaves, which is saturated at the leaf temperature $\left(q_{\text {sat }}\right)$. The canopy conductances for GPP and $E_{\mathrm{T}}$ both arise from diffusion through leaf stomatal pores, and therefore only differ by a constant factor of 1.6 (the square root of the ratio of the molecular masses of $\mathrm{CO}_{2}$ and $\mathrm{H}_{2} \mathrm{O}$ ).

$E_{\mathrm{T}}=1.6 g_{\mathrm{c}}\left(q_{\mathrm{sat}}-q_{\mathrm{a}}\right)$.

Changes in stomatal opening in response to changes in sunlight, atmospheric temperature and humidity, soil moisture, and $\mathrm{CO}_{2}$, are complex and uncertain (Berry et al., 2010), as are the scaling of these leaf-level responses up to the canopy and beyond (Piao et al., 2007; Jarvis and McNaughton, 1986; Jarvis, 1995). However, since stomatal behaviour affects transpiration and photosynthesis similarly, WUE is relatively insensitive to these uncertainties:

$\mathrm{WUE}=\frac{\left(C_{\mathrm{a}}-C_{\mathrm{i}}\right)}{1.6\left(q_{\mathrm{sat}}-q_{\mathrm{a}}\right)}=\frac{\left(C_{\mathrm{a}}-C_{\mathrm{i}}\right)}{1.6 D}=\frac{C_{\mathrm{a}}(1-f)}{1.6 D}$,

where $D$ is the atmospheric humidity deficit $\left(q_{\mathrm{sat}}-q_{\mathrm{a}}\right)$ and $f$ is the ratio of the internal to the external $\mathrm{CO}_{2}$ concentration $\left(C_{\mathrm{i}} / C_{\mathrm{a}}\right)$. This equation therefore expresses WUE in terms of atmospheric variables, $C_{\mathrm{a}}$ and $D$ (which itself depends on relative humidity and temperature), along with the factor $f$. The remaining uncertainty associated with plant physiology is therefore contained in $f$.

In the absence of water limitations, there is good evidence that $f$ is approximately independent of $C_{\mathrm{a}}$, so that $C_{\mathrm{i}}$ remains proportional to $C_{\mathrm{a}}$, unless $D$ changes (Jacobs, 1994; Katul et al., 2010; Leuning, 1995; Morison et al., 1983). Even during drought, $f$ will vary with $\mathrm{D}$, due in part to correlations between $D$ and soil moisture (Brodribb, 1996).
Stomatal optimization theories, which assume that stomata act so as to maximize photosynthesis for a given amount of available water (Cowan and Farquhar, 1977), also suggest that $f$ should depend predominantly on $C_{\mathrm{a}}$ and $D$ (Katul et al., 2010; Medlyn et al., 2011). Absolute values of WUE will depend on the nature of the vegetation and soil, such as the plant and soil hydraulics, but these optimization theories imply that there will be a near universal sensitivity of fractional changes in WUE to fractional changes in $C_{\mathrm{a}}$ and $D$ (see Supplement):

$\frac{\mathrm{WUE}}{\mathrm{WUE}(0)}=\left(\frac{C_{\mathrm{a}}}{C_{\mathrm{a}}(0)}\right)^{a}\left(\frac{D}{D(0)}\right)^{b}$,

where the subscript (0) denotes the initial state of each variable, and $a$ and $b$ are dimensionless coefficients. For given $a$ and $b$ values this equation describes how the fractional change in WUE at each location varies with fractional changes in $C_{\mathrm{a}}$ and $D$. Although they differ in their underlying assumptions and detailed conclusions, it is interesting to note that the latest stomatal optimization theories (Katul et al., 2010; Medlyn et al., 2011) both imply $a=1$ and $b=-0.5$ (see the Supplement).

We focus in this study on fractional changes in WUE, which are more likely to be independent of these complex factors. Therefore, we use two very different datasets of WUE, derived from tree-ring measurements and eddy covariance fluxes and aim to model the fractional changes in plant WUE by using atmospheric data alone. The longerterm climate signals are derived from the tree rings, spanning at least the last 100 years. Monthly WUE values are derived from eddy covariance observations between 1995 and 2006. We do not assume the applicability of stomatal optimization theories, but instead adopt equation 5 as a parsimonious empirical model for the fractional changes in WUE observed at each measurement site, given suitable fitting parameters $a$ and $b$. Tests using more elaborate statistical models, with additional environmental variables or vegetationspecific parameters, were not found to produce significant improvements in the fit to the observed changes in WUE despite the introduction of extra fitting parameters. Finally, we have compared our reconstruction of the fractional change in plant WUE to Earth System Models (ESMs) simulations, focussing on regional variations in the WUE changes and how these compare to the long-term tree-ring observations.

\section{Materials and methods}

We estimate the sensitivity of WUE to $C_{\text {a }}$ and $D$ by fitting to observed WUE changes inferred from both eddy covariance fluxes (relatively short records with high-temporal resolution) and carbon isotope records from tree rings (longerterm records with annual resolution). We use observations from 28 eddy covariance and 31 tree-ring sites (see Fig. 1 and the Supplement Tables S1 and S2). 


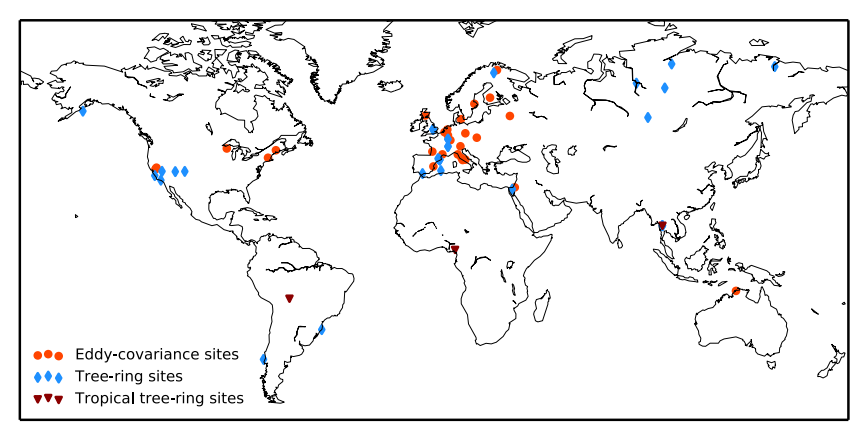

Figure 1. Locations of the eddy covariance flux sites and tree-ring sites used (see Table S2 and S3 in the Supplement for a list of the sites). Tropical tree-ring sites are used as independent data sources for comparison.

\subsection{Eddy covariance observations}

The carbon and water flux observations were taken from the Free Fair-use Fluxnet database (www.fluxdata.org) (Baldocchi, 2008; Papale et al., 2006; Reichstein et al., 2005). We selected a total of 28 sites based on data availability (Table S1 in the Supplement). Monthly WUE was estimated from Eq. (1) with GPP used directly from the database (Reichstein et al., 2005). In general the total latent heat flux (LE) has contributions from interception loss, soil evaporation and transpiration. We follow previous studies (Dekker et al., 2001; Groenendijk et al., 2011; Keenan et al., 2013; Law et al., 2002) in assuming that the latent heat flux is dominated by transpiration during periods with no rain in the preceding 2 days, when the interception loss and soil evaporation are assumed small. Monthly average values of GPP, $E_{\mathrm{T}}$, $C_{\mathrm{a}}, D$ and $T$ were calculated from half-hourly observations (not gap-filled) during dry periods (i.e. no rain in the preceding 2 days) when GPP was larger than zero. To exclude periods with unrealistic WUE values due to the division by very small $E_{\mathrm{T}}$ values, we used only months during the growing season. Annual average growing season values were calculated from the months with an average temperature above $10^{\circ} \mathrm{C}$. Only sites with at least six annual values were used, resulting in a dataset of 222 annual growing season values of WUE, $C_{\text {a }}$ and $D$. Data are used between 1995 and 2006. Fractional changes were calculated relative to the mean over the observational period for each of the sites, to enable comparison between sites.

\subsection{Tree-ring observations}

To derive a longer-term relationship between the fractional change in WUE and variations in $C_{\mathrm{a}}$ and $D$, we used $\Delta^{13} \mathrm{C}$ tree-ring observations from 31 locations (Fig. 1), ranging from 1900 to current, as described in two previous studies (Franks et al., 2013; Hemming et al., 1998) (see the Supplement, Table S2). The discrimination of ${ }^{12} \mathrm{C}$ against ${ }^{13} \mathrm{C}$ $\left(\Delta^{13} \mathrm{C}\right)$ is estimated from the tree-ring samples (Hemming et al., 1998; van der Sleen et al., 2015). The $\Delta^{13} \mathrm{C}$ measurements can be used to estimate the ratio of the internal to the external $\mathrm{CO}_{2}$ concentration $\left(f=C_{\mathrm{i}} / C_{\mathrm{a}}\right)$ using the relationship $f=\left(\Delta^{13} \mathrm{C}-4.4\right) /(27-4.4)$, where $\Delta^{13} \mathrm{C}$ is in parts per thousand (\%o), and $C_{\mathrm{a}}$ is taken from the Mauna Loa atmospheric $\mathrm{CO}_{2}$ record (Farquhar et al., 1989; Franks et al., 2013; Keeling et al., 1976). WUE is estimated with Eq. (4) using annual average growing season values of $D$ from the CRU dataset, taking the nearest pixel to each site (Harris et al., 2013). This large-scale dataset for $D$ ensures consistency among the sites, but may underestimate the finer spatial variation in $D$. As for the eddy covariance sites, we estimated the fractional changes relative to the mean over the observational period at each of the sites. For this analysis we have 1007 observations of WUE derived from tree-ring observations of $\Delta^{13} \mathrm{C}$.

\subsection{Fractional WUE}

To estimate $a$ and $b$ with a linear regression model we rewrite Eq. (5) in a logarithmic form:

$\ln \left\{1+\frac{\Delta \mathrm{WUE}}{\mathrm{WUE}(0)}\right\}=a \ln \left\{1+\frac{\Delta C_{\mathrm{a}}}{C_{\mathrm{a}}(0)}\right\}+b \ln \left\{1+\frac{\Delta D}{D(0)}\right\}$.

Here the second term in each bracket represents the fractional change in WUE, $C_{\mathrm{a}}$ and $D$, respectively. These fractional change variables are used in all our subsequent statistical analyses and modelling. We set out to fit the fractional change in WUE at each observation site (Fig. 1) from the fractional change in $C_{\mathrm{a}}$ and the fractional change in $D$. For comparison and fitting we therefore need to calculate WUE(0), $C_{\mathrm{a}}(0)$ and $D(0)$ for the observational data, which we take as the mean over the entire observational record available at each site.

\subsection{Global fractional change of WUE}

The dependence of fractional changes in WUE on $C_{\mathrm{a}}$ and $D$ allows us to use these relationships to estimate changes in WUE at large scales using global climate data. The fractional change in $D$ can be further partitioned into a change in temperature $(T)$ and relative humidity (RH), which makes it possible to separate the effect of changes in these variables on WUE (see the Supplement). To do this, we used the CRU climate dataset (Harris et al., 2013) at a $0.5^{\circ} \times 0.5^{\circ}$ latitude/longitude grid and the annual $\mathrm{CO}_{2}$ concentration at Mauna-Loa (Keeling et al., 1976) to derive the global and local variation in WUE. We only used months during the growing season when photosynthesis occurs, assumed to be above a monthly average temperature threshold of $10^{\circ} \mathrm{C}$, where we assemed photosynthesis to be above a monthly. For the period 1900-1930 the average temperature was calculated for each month from which a spatial mask was generated (see Supplement Fig. S4). This mask was then used to calculate 
annual time-evolving values of WUE from the growing season values of temperature and humidity for each year between 1901 and 2010.

\subsection{Other independent data sources}

For three locations, western North America, western Europe and East Asia, we have compared our simulated fractional change in plant WUE with remote-sensing (RS) products of GPP and $E_{\mathrm{T}}$ (Jung et al., 2011). This dataset covers the period 1982-2006; we use the period 1986-1990 as a reference period for both our estimate and the fractional change in WUE from the RS product. As the RS data do not cover a response to changes in $C_{\mathrm{a}}$, we estimated the fractional change in WUE with and without the $C_{\mathrm{a}}$ response.

At the global scale, we have compared our simulated fractional change in plant WUE with simulations of Earth System Models (ESMs). Most of the latest ESMs calculate changes in both GPP and $E_{\mathrm{T}}$. This allows a comparable change in WUE to be calculated for 28 CMIP5 models (Taylor et al., 2012) based-on their historical simulations. Finally, regional differences in responses are compared to the 31 treering observation sites.

\section{Results and discussion}

Figure 2 summarizes the derivation of the $a$ and $b$ parameters, which are the sensitivity of WUE to $C_{\mathrm{a}}$ and $D$, for the tree-ring and eddy covariance observations. In general, eddy covariance data alone are unable to fully constrain the $\mathrm{CO}_{2}$ sensitivity of the WUE (Keenan et al., 2013), because the data records are too short to sample significant changes in $\mathrm{CO}_{2}$, resulting in a value of $a$ of $0.79 \pm 0.79$ for all eddy covariance sites (see Supplement Fig. S1 and Table S3). However, the longer tree-ring records overall yield a good constraint on $a$ of $1.61 \pm 0.54$. The annual data points for the two datasets can be combined into a single dataset. Fitting against this more complete dataset gives generic sensitivity coefficients of $a=1.51 \pm 0.57$ and $b=-0.72 \pm 0.16$. These values are mainly constrained by the tree-ring observations for which the fits to Eq. (6) are more tightly defined (Fig. 2a and Supplement Fig. S1 top row).

A value of $a$ larger then 1, suggests that WUE has been increasing even faster than the atmospheric $\mathrm{CO}_{2}$ concentration (Fig. 2c). This is qualitatively consistent with conclusions from a previous study, which was based purely on eddy covariance data (Keenan et al., 2013), but is more robustly demonstrated here due to the much longer tree-ring records.

It is interesting to note that our overall values of $a=$ $1.51 \pm 0.57$ and $b=-0.72 \pm 0.16$ are larger by about $50 \%$ than the values derived from stomatal optimization theories: $a=1.0, b=-0.5$ (Cowan and Farquhar, 1977; Katul et al., 2010; Palmroth et al., 2013), indicating a stronger response to changes in both $\mathrm{CO}_{2}$ and climate. Such theoretical sensitivities are common to variants of stomatal optimization theory, including those that assume either electron transport-limited or Rubisco-limited photosynthesis, and even when additional nitrogen limitations are accounted for Prentice et al. (2014). The differences between the optimization theory and our empirically derived WUE sensitivities may arise from differences between leaf-surface and atmospheric values of $\mathrm{CO}_{2}$ and humidity, but they may also be indicative of missing constraints and feedbacks in the optimization theories (Lin et al., 2015; Prentice et al., 2014; de Boer et al., 2011, 2016).

\subsection{Testing more elaborate statistical models}

Equation (6) is motivated by empirical evidence and theory suggesting that WUE should vary predominantly with $C_{\mathrm{a}}$ and $D$. However, it is conceivable that the fractional change in WUE could also depend on other environmental conditions or the detailed vegetation type. In order to test for this, we carried out two additional sets of fits against the observational data. In the first test we extended our statistical model (Eq. 6) to include other environmental variables that had been measured at the Fluxnet sites, most notably solar radiation, air temperature, and soil water content. Including these additional predictor variables does not significantly improve the fit to the observed changes in WUE (as measured by $r^{2}$ ), and typically results in less robust predictions (as measured by the adjusted $r^{2}$ ), because of the introduction of extra fitting parameters (see the Supplement, Table S4). In the second test, we carried out separate statistical fits for each of the sites listed in the Fluxnet dataset. Clustering of these values by vegetation type would indicate that $a$ and $b$ parameters are dependent on vegetation type, but we find no evidence of such clustering (Fig. 3).

\subsection{Comparison to independent WUE estimates.}

Our best-fit generic $a$ and $b$ parameters are able to reasonably reproduce the fractional changes in WUE due to fractional changes in both $C_{\mathrm{a}}$ and $D$ across the 59 tree-ring and eddy covariance sites (see Supplement Fig. S2). However, it is important to evaluate the estimated response of WUE to $C_{\mathrm{a}}$ and $D$ against independent data. We compared the change in WUE estimated with the best-fit parameters to observations at three tropical tree-ring sites from a recent study (van der Sleen et al., 2015). At these sites a range of species of both trees and under-storey were sampled. Our estimate for these three locations passes close to the mean of the observed WUE fractional changes (Fig. 4a-c). Because the RS data do not include a response to changes in $C_{\mathrm{a}}$, we estimated a fractional change in WUE with and without this response (Fig. 4d-f) for three regions, which show distinct changes in WUE: western North America, western Europe and East Asia. The RS fluxes show little inter-annual variability, and much less variability than we estimate. For the three regions in Fig. 4d-f our estimates with and without $\mathrm{CO}_{2}$ effects sit on either side of the RS estimates. In the Amazon, South Africa 

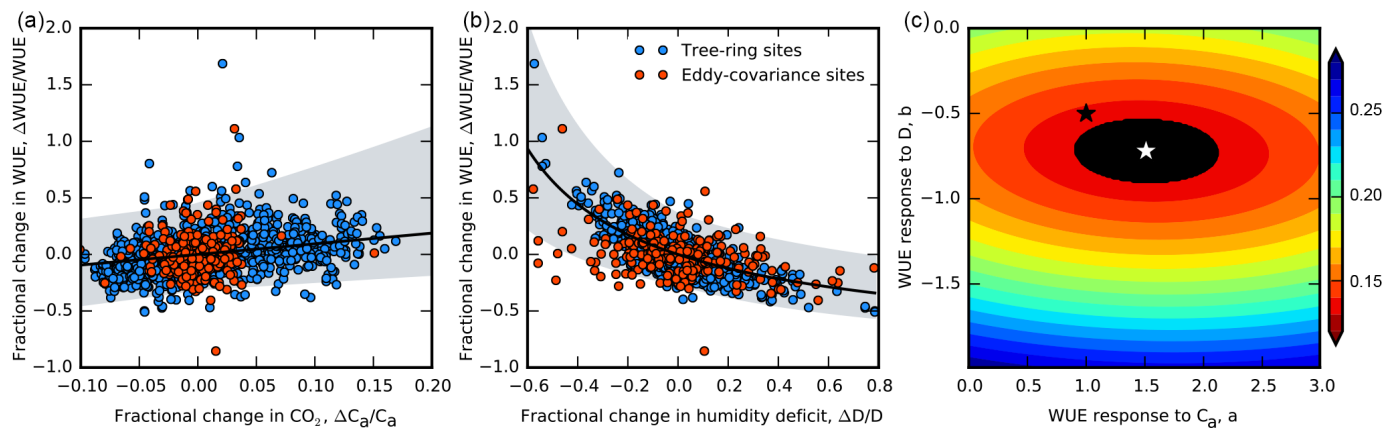

Figure 2. Water-use efficiency (WUE) from tree-ring and eddy covariance observations. The relationship between the observed fractional change in WUE and the fractional change in (a) $\mathrm{CO}_{2}$ concentration and (b) humidity deficit of both datasets is fitted to Eq. (3),with best-fit values for $a(1.51 \pm 0.57)$ and $b(-0.72 \pm 0.16)$. (c) The colours show the root mean square error (RMSE) of the simulated vs. observed fractional change in WUE as a function of $a$ and $b$, with the black area representing the best parameters within $5 \%$ of the RMSE of the best fit (white star). The black star represents the values according to the optimality hypothesis.

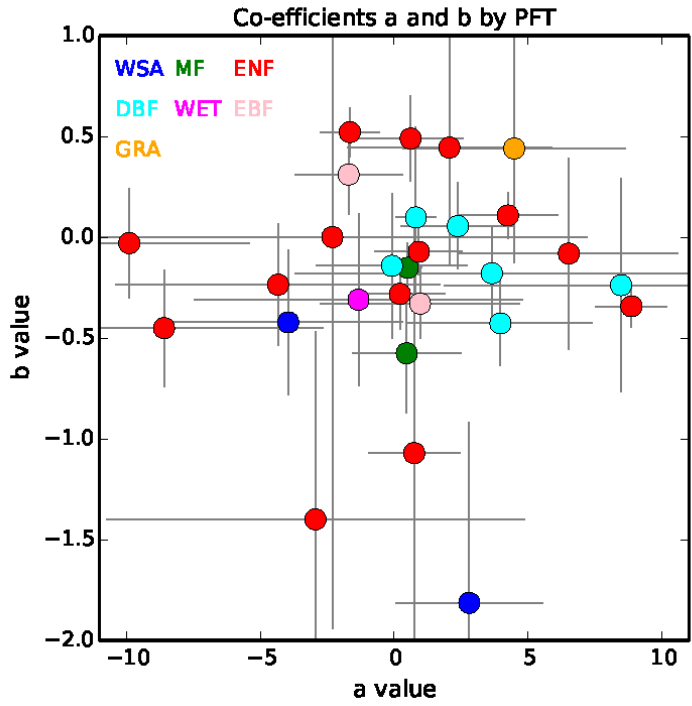

Figure 3. Comparison of best-fit $a$ and $b$ parameters (see Eq. 5) by plant functional type (PFT). Here the sites are organized by dominant PFT, using classifications used for the FluxNet sites: evergreen broadleaf forest (EBF), evergreen needleleaf forest (ENF), grassland (GRA), mixed forest (MF), wetland (WET) and woody savannah (WSA).

and South-East Asia (see Supplement Fig. S3), our estimates excluding $\mathrm{CO}_{2}$ effects are similar to the RS estimates; whilst the inclusion of $\mathrm{CO}_{2}$ effects leads to significant increases in WUE (see Supplement Fig. S3) that appear to be inconsistent with the RS estimates (which do not account for $\mathrm{CO}_{2}$ changes), but are more consistent with the tree-ring (Franks et al., 2013) and eddy covariance data (Keenan et al., 2013).

\subsection{Global fractional change of WUE}

Globally, we estimate that WUE has increased by $48 \pm 22 \%$ since 1900 (Fig. 5a), with the $\mathrm{CO}_{2}$ increase con- tributing $+47 \pm 21 \%$ and relative humidity contributing $+3.6 \pm 1.3 \%$, counteracted by a much smaller reduction in WUE due to a warming of $-2.3 \pm 0.8 \%$. Estimated fractional changes in WUE between 1901-1930 and 2001-2010 differ regionally between 0.1 and 0.6 (Fig. 5 b). Uncertainties in global WUE changes were derived from the range of the parameters $a$ and $b$ within $5 \%$ of the RMSE of our best fit (Fig. 2c).

\subsection{Comparison to simulations with complex Earth System Models (ESMs)}

The CMIP5 models simulate an increase in WUE of between $2 \%$ and $28 \%$ to 2005 , with an ensemble mean of $14 \%$ (see the Supplement, Table S5). For comparison, our overall fit against the tree-ring and eddy covariance data indicates an approximately $40 \%$ increase in WUE over the same period. Figure 6 compares the annual time series of the fractional changes in WUE from the CMIP5 models (black line and green uncertainty plumes), our statistical fit (orange lines), and the mean changes observed for the tree-ring (black marks and grey uncertainty bars) and eddy covariance sites (dark blue marks and light blue uncertainty bars). This comparison suggests that the latest ESMs significantly underestimate the historical increase in WUE.

\subsection{Regional changes in WUE}

Our global average change in WUE hides substantial regional differences (Fig. 5b). This is a result of the spatially and temporally varying impact of climate change on WUE (Fig. 7a and animation in the Supplement), driven by the heterogeneity of the warming (Fig. 7b) and the large variation in changes in near-surface RH (Fig. 7c). In many regions the overall impact is a significant increase in WUE, such as western North America (Fig. 7d). However, the recent rate of increase has declined substantially in several heavily popu- 

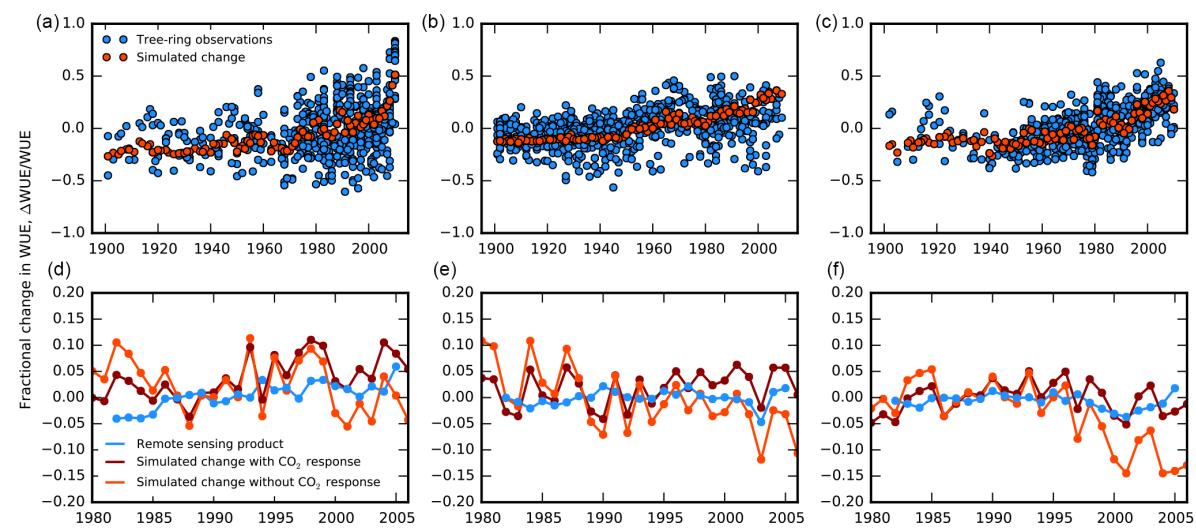

Figure 4. Comparison of estimated water-use efficiency trends to independent observations. Simulated fractional change in WUE (orange) compared to observations for three tropical tree-ring sites in Bolivia (a), Cameroon (b) and Thailand (c) (blue, van der Sleen 2015). Simulated fractional change in WUE for (d) western North America, (E) western Europe and (F) East Asia, with (dark red) and without (orange) $\mathrm{CO}_{2}$ effect, compared to the WUE trend derived from a remote sensing product of carbon uptake and water loss (Jung et al., 2011). The location of the tree-ring sites is presented in Fig. S1 and the regions (d)-(f) are as in Fig. 5.
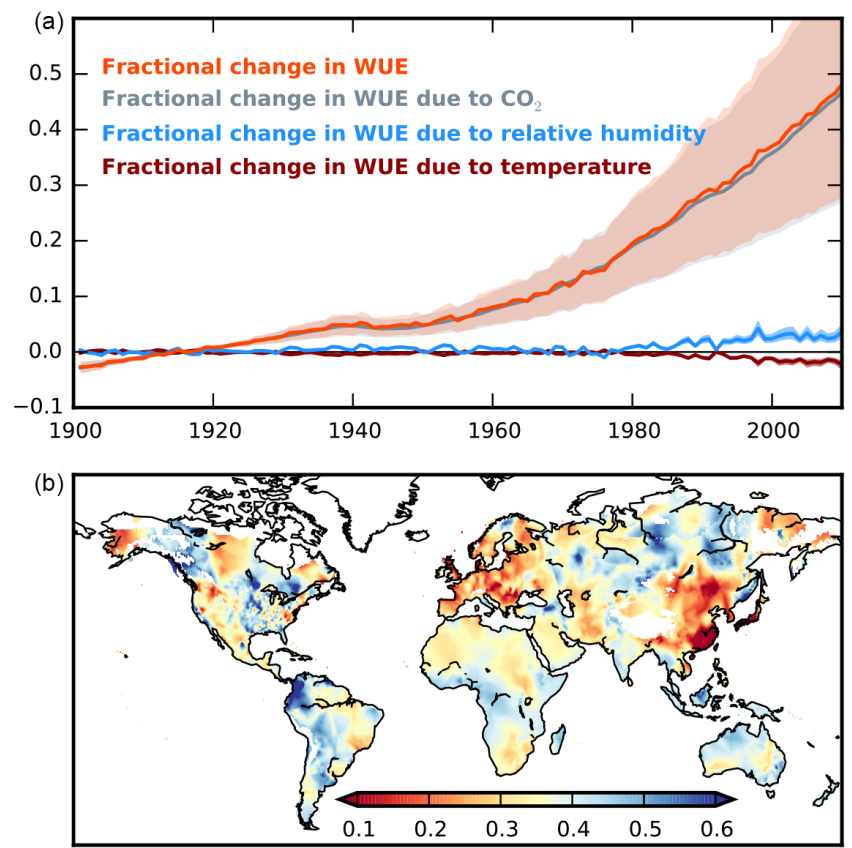

Figure 5. 20th century fractional change of water-use efficiency (WUE). (a) Time series of the estimated global fractional change in WUE (orange, relative to the average over 1901-1930) partitioned into the effects of changes in $\mathrm{CO}_{2}$, relative humidity and temperature. (b) Spatial pattern of the estimated fractional change in WUE between 1901-1930 and 2001-2010. These calculations use observed monthly surface air temperature and vapour pressure (Harris et al., 2013) during the growing season, and annual atmospheric $\mathrm{CO}_{2}$ concentrations at Mauna Loa (Keeling et al., 1976).

lated regions. For example, WUE shows a slower increase in western Europe since the 1980s, as a result of increases in $T$, which has counteracted the WUE increase due to increasing

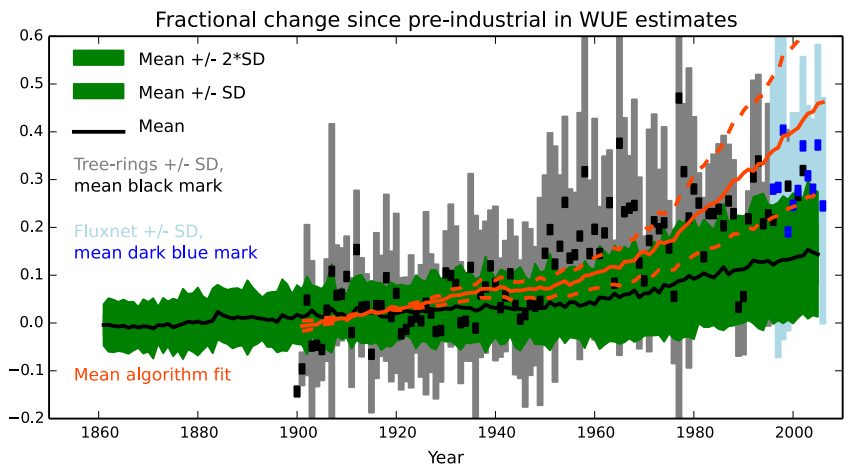

Figure 6. Comparison of measured and modelled fractional changes in WUE from 1860 to 2010. Estimates from tree-rings and eddy covariance data are shown by the black and blue points respectively, with the bars in each case showing \pm 1 standard deviation about the mean response. The results from complex coupled Earth System Models are shown by the black continuous line and the green plume (with dark green showing 1 standard deviation and light green showing 2 standard deviations). The algorithm presented in this paper, which estimates fractional WUE changes from changes in $\mathrm{CO}_{2}$ concentration and humidity deficit alone (Eq. 6), is shown by the orange lines. To enable the comparison between these different estimates, we normalized over common overlapping periods (for the tree-ring data and model simulations - 1900-1930; for the tree-ring and eddy covariance data - the period of overlap when at least three eddy covariance sites are available).

$\mathrm{CO}_{2}$ (Fig. 7e). This is also observed in WUE trends derived from isotopic tree-ring observations in Spain (Linares and Camarero, 2012). Our analysis indicates that East Asia has suffered an even more significant suppressions of WUE since about 1990, due predominantly to reductions in RH (Wang et al., 2012) (Fig. 7f). This pattern of changing RH is compa- 

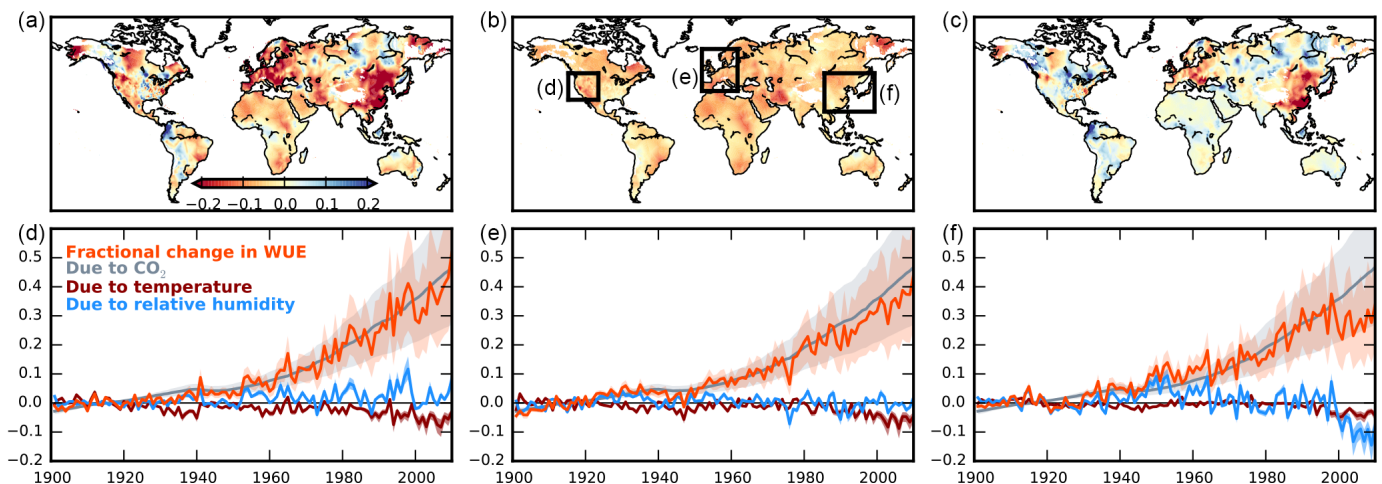

Figure 7. Changes in WUE arising from climate variables. Spatial patterns of the fractional changes in WUE arising from changes in (a) climate, i.e. both temperature and relative humidity (RH) together, (b) temperature alone, and (c) RH alone, between 1901-1930 and 2001-2010. Time-series are as in Fig. 5 for (d) western North America, (e) western Europe and (f) East Asia, which show the large regional and temporal variations in these climate-driven changes in WUE.

rable with the trends in precipitation and drought since 1950 (Dai, 2011).

For the 31 tree-ring observation sites, we have plotted the ensemble mean regional ESM model results against the individual observed tree-ring data (Fig. S5 in the Supplement). For 10 out of 31 observation sites, the simulated fractional WUE increases between 5 and $10 \%$. For 3 out of the 31 sites, the fractional WUE increases by more than $50 \%$, and for 14 out of the 31 observation sites the WUE change inferred from the tree-ring data is significantly higher than that simulated by the ESMs.

\section{Conclusions}

This study shows that fractional changes in plant WUE, at large scales and over the period of the climatological record, can be inferred from atmospheric data alone. By combining two very different datasets of WUE derived from tree-ring $\Delta{ }^{13} \mathrm{C}$ measurements and eddy covariance fluxes we have derived a consistent response of the fractional change in WUE to the fractional changes in $C_{\mathrm{a}}$ and $D$. This generic response can be used to estimate WUE changes over the entire period of the atmospheric record. Our analysis shows that global WUE increased by approximately a half over the 20th century predominantly due to rising $\mathrm{CO}_{2}$, which is significantly more than is simulated by the latest Earth System Models. However, this increase in WUE has been modulated downwards in recent decades by the impact of climate change. This is especially true for the highly populated regions of western Europe and East Asia, where reductions in atmospheric relative humidity and increases in temperature have acted to offset increases in WUE due to increasing $\mathrm{CO}_{2}$. We conclude that the effects of increasing $\mathrm{CO}_{2}$ on plant WUE are significantly underestimated in the latest climate projections.

\section{The Supplement related to this article is available online at doi:10.5194/esd-7-525-2016-supplement.}

Acknowledgements. The contributions of M. Groenendijk, C. Huntingford, and P. M. Cox were funded by the UK Natural Environment Research Council (NERC) HYDRA project. We thank Margaret Barbour for providing tree-ring data compiled from many different sources. This work used eddy covariance data acquired by the FLUXNET community and in particular by the following networks: AmeriFlux (US Department of Energy, Biological and Environmental Research, Terrestrial Carbon Program (DE-FG02-04ER63917 and DE-FG02-04ER63911)), AfriFlux, AsiaFlux, CarboAfrica, CarboEuropeIP, Carboltaly, CarboMont, ChinaFlux, Fluxnet-Canada (supported by CFCAS, NSERC, BIOCAP, Environment Canada, and NRCan), GreenGrass, KoFlux, LBA, NECC, OzFlux, TCOS-Siberia, USCCC. We acknowledge the financial support to the eddy covariance data harmonization provided by CarboEuropeIP, FAO-GTOS-TCO, iLEAPS, Max Planck Institute for Biogeochemistry, National Science Foundation, University of Tuscia, Université Laval and Environment Canada and US Department of Energy and the database development and technical support from Berkeley Water Center, Lawrence Berkeley National Laboratory, Microsoft Research eScience, Oak Ridge National Laboratory, University of California - Berkeley, University of Virginia.

Edited by: G. Bala

\section{References}

Ainsworth, E. A. and Rogers, A.: The response of photosynthesis and stomatal conductance to rising $\left[\mathrm{CO}_{2}\right]$ : mechanisms and environmental interactions, Plant Cell Environ., 30, 258-270, 2007.

Baldocchi, D. D.: Breathing of the terrestrial biosphere: lessons learned from a global network of carbon dioxide flux measurement systems, Aust. J. Bot., 56, 1-26, 2008. 
Berry, J., Beerling, D. J., and Franks, P. J.: Stomata: key players in the earth system, past and present, Curr. Opin. Plant Biol., 13, 233-240, 2010.

Betts, R. A., Boucher, O., Collins, M., Cox, P. M., Falloon, P. D., Gedney, N., Hemming, D. L., Huntingford, C., Jones, C. D., Sexton, D. M. H., and Webb, M. J.: Projected increase in continental runoff due to plant responses to increasing carbon dioxide, $\mathrm{Na}$ ture, 448, 1037-U5, 2007.

de Boer, H. J., Lammertsma, E. I., Wagner-Cremer, F., Dilcher, D. L., Wassen, M. J., and Dekker, S. C.: Climate forcing due to optimization of maximal leaf conductance in subtropical vegetation under rising $\mathrm{CO}_{2}$, P. Natl. Acad. Sci. USA, 108, 4041-4046, 2011.

de Boer, H. J., Price, C. A., Wagner-Cremer, F., Dekker, S. C., Franks, P. J., and Veneklaas, E. J.: Optimal allocation of leaf epidermal area for gas exchange, New Phytol., 1219-1228, doi:10.1111/nph.13929, 2016.

Brodribb, T.: Dynamics of changing intercellular $\mathrm{CO}_{2}$ concentration (ci) during drought and determination of minimum functional ci, Plant Physiol., 111, 179-185, 1996.

Cowan. I. and Farquhar, G.: Stomatal function in relation to leaf metabolism and environment, Soc Exp. Biol. Symp., 31, 471505, 1977.

Cowan, I. R.: An electrical analogue of evaporation from, and flow of water in plants, Planta, 106, 221-226, 1972.

Dai, A.: Drought under global warming: a review, Wires Clim. Change, 2, 45-65, 2011.

Dekker, S. C., Bouten, W., and Schaap, M. G.: Analysing forest transpiration model errors with artificial neural networks, J. Hydrol., 246: 197-208, 2001.

Farquhar, G., Ehleringer, J. R., and Hubick, K. T.: Carbon isotope discrimination and photosynthesis, Annu. Rev. Plant. Physiol. Plant Mol. Biol., 40, 503-537, 1989.

Field, C. B., Jackson, R. B., and Mooney, H.: Stomatal responses to increased $\mathrm{CO}_{2}$ : implications from the plant to the global-scale, Plant Cell Environ., 18, 1214-1225, 1995.

Franks, P. J., Adams, M. A., Amthor, J. S., Barbour, M. M., Berry, J. A., Ellsworth, D. S., Farquhar, G. D., Ghannoum, O., Lloyd, J., McDowell, N., Norby, R.J., Tissue, D. T., and von Caemmerer, S.: Sensitivity of plants to changing atmospheric $\mathrm{CO}_{2}$ concentration: from the geological past to the next century, New Phytol., 197, 1077-1094, 2013.

Gedney, N., Cox, P. M., Betts, R. A., Boucher, O., Huntingford, C., and Stott, P. A.: Detection of a direct carbon dioxide effect in continental river runoff records, Nature, 439, 835-838, 2006.

Groenendijk, M. Dolman, A. J., Ammann, C., Arneth, A., Cescatti, A., Dragoni, D., Gash, J. H. C., Gianelle, D., Gioli, B., Kiely, G., Knohl, A., Law, B. E., Lund, M., Marcolla, B., Van Der Molen, M. K., Montagnani, L., Moors, E., Richardson, A. D., Roupsard, O., Verbeeck, H., and Wohlfahrt, G.: Seasonal variation of photosynthetic model parameters and leaf area index from global Fluxnet eddy covariance data, J. Geophys. Res., 116, 118, doi:10.1029/2011JG001742, 2011.

Harris, I., Jones, P. D., Osborn, T. J., and Lister, D. H.: Updated high-resolution grids of monthly climatic observationsthe CRU TS3.10 Dataset, Int. J. Climatol., 34, 623-1642, doi:10.1002/joc.3711, 2013.

Hemming, D. I., Switsur, V. R., Waterhouse, J. S., Heaton, T. H. E., and Carter, A. H. C.: Climate variation and the stable carbon isotope composition of tree ring cellulose: an intercomparison of Quercus robur, Fagus sylvatica and Pinus silvestris, Tellus B, 50, 25-33, 1998.

Jacobs, C. M. J.: Direct impact of atmospheric $\mathrm{CO}_{2}$ enrichment on regional transpiration. Dissertation, Wageningen, 179 pp., 1994.

Jarvis, P. G.: Scaling processes and problems, Plant Cell Environ., 18, 1079-1089, 1995.

Jarvis, P. G. and McNaughton, K. G.: Stomatal control of transpiration - Scaling up from leaf to region, Adv. Ecol. Res., 15, 1-49, 1986.

Jung, M., Reichstein, M., Margolis, H. A., Cescatti, A., Richardson, A. D., Arain, M. A., Arneth, A., Bernhofer, C., Bonal, D., Chen, J., Gianelle, D., Gobron, N., Kiely, G., Kutsch, W., Lasslop, G., Law, B. E., Lindroth, A., Merbold, L., Montagnani, L., Moors, E. J., Papale, D., Sottocornola, M., Vaccari, F., and Williams, C.: Global patterns of land-atmosphere fluxes of carbon dioxide, latent heat, and sensible heat derived from eddy covariance, satellite, and meteorological observations, J. Geophys. Res., 116, 1-16, doi:10.1029/2010JG001566, 2011.

Katul, G., Manzoni, S., Palmroth, S., and Oren, R.: A stomatal optimization theory to describe the effects of atmospheric $\mathrm{CO}_{2}$ on leaf photosynthesis and transpiration, Ann. Botany, 105, 431442, 2010.

Keeling C. D., Bacastow, R. B., Bainbridge, A. E., Ekdahl Jr., C.. A., Guenther, P. R., Waterman, L. S., and Chin, J. F. S.: Atmospheric carbon dioxide variations at Mauna Loa Observatory, Hawaii, Tellus, 28, 538-551, 1976.

Keenan T. F., Hollinger, D. Y., Bohrer, G., Dragoni, D., Munger, J. W., Schmid, H. P., Richardson, A. D., Keeling, B. C. D., Bacastow, R. B., Bainbridge, A. E., Ekdahl, C. A., Guenther, P. R., and Waterman, L. E. E. S.: Increase in forest water-use efficiency as atmospheric carbon dioxide concentrations rise, Nature, 499, 324-327, 2013.

Law, B. E., Falge, E., Gu, L., Baldocchi, D. D., Bakwin, P., Berbigier, P., Davis, K., Dolman, A. J., Falk, M., Fuentes, J. D., Goldstein, A., Granier, A., Grelle, A., Hollinger, D., Janssens, I. A., Jarvis, P., Jensen, N. O., Katul, G., Mahli, Y., Matteucci, G., Meyers, T., Monson, R., Munger, W., and Oechel, W.: Environmental controls over carbon dioxide and water vapor exchange of terrestrial vegetation, Agr. For. Meteorol., 113, 97-120, 2002.

Leuning, R.: A critical appraisal of a combined stomatalphotosynthesis model for $\mathrm{C}_{3}$ plants, Plant Cell Environ., 18, 339355, 1995.

Lin, Y.-S., Medlyn, B. E., Duursma, R. A., Prentice, I. C., Wang, H., Baig, S., Eamus, D., de Dios, V. R., Mitchell, P., Ellsworth, D. S., de Beeck, M. O., Wallin, G., Uddling, J., Tarvainen, L., Linderson, M.-L., Cernusak, L. A., Nippert, J. B., Ocheltree, T. W., Tissue, D. T., Martin-StPaul, N. K., Rogers, A., Warren, J. M., De Angelis, P., Hikosaka, K., Han, Q., Onoda, Y., Gimeno, T. E., Barton, C. V. M., Bennie, J., Bonal, D., Bosc, A., Löw, M., Macinins-Ng, C., Rey, A., Rowland, L., Setterfield, S. A., TauszPosch, S., Zaragoza-Castells, J., Broadmeadow, M. S. J., Drake, J. E., Freeman, M., Ghannoum, O., Hutley, L. B., Kelly, J. W., Kikuzawa, K., Kolari, P., Koyama, K., Limousin, J.-M., Meir, P., Lola da Costa, A. C., Mikkelsen, T. N., Salinas, N., Sun, W., and Wingate, L.: Optimal stomatal behaviour around the world, Nat. Clim. Chang., 5, 459-464, doi:10.1038/nclimate2550, 2015. 
Linares, J. C. and Camarero, J. J.: From pattern to process: linking intrinsic water-use efficiency to drought-induced forest decline, Global Chang. Biol., 18, 1000-1015, 2012.

Medlyn, B. E. Duursma, R. A., Eamus, D., Ellsworth, D. S., Prentice, I. C., Barton, C. V. M., Crous, K. Y., De Angelis, P., Freeman, M., and Wingate, L.: Reconciling the optimal and empirical approaches to modelling stomatal conductance, Global Chang. Biol., 17, 2134-2144, doi:10.1111/j.1365-2486.2010.02375.x, 2011.

Morison, J. I. L. and Gifford, R. M.: Stomatal sensitivity to carbon dioxide and humidity, Plant Physiol., 71, 789-796, 1983.

Norby, R. J., Warren, J. M., Iversen, C. M., Medlyn, B. E., and McMurtrie, R. E.: $\mathrm{CO}_{2}$ enhancement of forest productivity constrained by limited nitrogen availability, P. Natl. Acad. Sci. USA107:19368-19373, 2010.

Palmroth, S., Katul, G. G., Maier, C. A., Ward, E., Manzoni, S., and Vico, G: On the complementary relationship between marginal nitrogen and water-use efficiencies among Pinus taeda leaves grown under ambient and $\mathrm{CO}_{2}$-enriched environments, Ann. Botany, 111, 467-477, 2013.

Papale, D., Reichstein, M., Aubinet, M., Canfora, E., Bernhofer, C., Kutsch, W., Longdoz, B., Rambal, S., Valentini, R., Vesala, T., and Yakir, D.: Towards a standardized processing of Net Ecosystem Exchange measured with eddy covariance technique: algorithms and uncertainty estimation, Biogeosciences, 3, 571-583, doi:10.5194/bg-3-571-2006, 2006.

Piao, S., Friedlingstein, P., Ciais, P., de Noblet-Ducoudre, N., Labat, D., and Zaehle, S.: Changes in climate and land use have a larger direct impact than rising $\mathrm{CO}_{2}$ on global river runoff trends, $\mathrm{P}$. Natl. Acad. Sci. USA, 104, 15242-15247, 2007.
Prentice, I. C., Dong, N., Gleason, S. M., Maire, V., and Wright, I. J.: Balancing the costs of carbon gain and water transport: testing a new theoretical framework for plant functional ecology, Ecol Lett., 17, 82-91, 2014.

Reichstein, M., Falge, E., Baldocchi, D., Papale, D., Aubinet, M., Berbigier, P., Bernhofer, C., Buchmann, N., Gilmanov, T., Granier, A., Grünwald, T., Havrínkov, K., Ilvesniemi, H., Janous, D., Knohl, A., Laurila, T., Lohila, A., Loustau, D., Matteucci, G., Meyers, T., Miglietta, F., Ourcival, J. M., Pumpanen, J., Rambal, S., Rotenberg, E., Sanz, M., Tenhunen, J., Seufert, G., Vaccari, F., Vesala, T., Yakir, D., and Valentini, R.: On the separation of net ecosystem exchange into assimilation and ecosystem respiration: review and improved algorithm, Global Change Biol., 11, 1424-1439, 2005.

Taylor, K. E., Stouffer, R. J., and Meehl, G.: An Overview of CMIP5 and the Experiment Design, Bull. Am. Meteorol. Soc., 93, 485498, doi:10.1175/BAMS-D-11-00094.1, 2012.

van der Sleen, P., Groenendijk, P., Vlam, M., Anten, N. P. R., Boom, A., Bongers, F., Pons, T. L., Terburg, G., and Zuidema, P. A.: No growth stimulation of tropical trees by 150 years of $\mathrm{CO}_{2}$ fertilization but water-use efficiency increased, Nat. Geosci., 8, 24-28, 2015.

Wang, K., Dickinson, R. E., and Liang, S.: Global atmospheric evaporative demand over land from 1973 to 2008, J. Climate, 25, 8353-8361, 2012. 